\title{
15. SEVEN YEARS EXPERIENCE AND ANALYSIS ON CORPORATED- WIDE DISTANCE LEARNING FOR ENGINEERS USING SATELLITE COMMUNICATIONS
}

\author{
Kouji Yoshida, Asako Nishio, Hiroshi Hisha, \\ Harumasa Tohda, Tadashi Odaka and Masahiro \\ Kasuga \\ Institute of Technology, \\ Mitsubishi Electric Corporation \\ 2-1, Akashia-dai 2-chome, \\ Sanda-shi, 669-1323 JAPAN \\ Fax: 81-4-6741-2649 \\ Email:yoshidak@hit.isl.melco.co.jp,
} asako,hisha,tohda,odaka(@iot.melco.co.jp),ka suga@gad.saib.melco.co.jp

\begin{abstract}
At Mitsubishi Electric Corporation, a corporate-wide educational system using satellite communications has been rapidly rein forced since 1990, to meet a wide range of various technical demands to its nation-wide entities including the affiliated ones. It mainly provides 'knowledge-based' courses, in parallel to the 'discussion-based' mid-level and/or advanced ones, long provided at three education centers since 1983. Over the last seven years, in the number of participants the satellite communications system achieved remarkable increase with minimum per-recipient cost.

A series of questionnaires made on the participants shows that, education through effective use of satellite communications is as effective as a center-based one. It has also revealed several distinctive features of the education using satellite communications, i.e. the importance of well-organized and suitable textbooks, and tailored lecturing materials provided by means of visual images such as in-house videos.

In recent years, the system has further adopted bidirectional communications by effectively implementing the fiber-optic corporate VAN. In order to satisfy the day-to-day educational needs in various engineering fields, which include information technology, the company has added providing the intranet and mailing list services.
\end{abstract}

The original version of this chapter was revised: The copyright line was incorrect. This has been corrected. The Erratum to this chapter is available at DOI: 10.1007/978-0-387-35393-7_22 


\section{Keywords \\ Distance learning, Internet, Networks, Satellites}

\section{Introduction}

The objective of Mitsubishi Electric Corporation is "to contribute to society with excellent technology and creativity." , and to realize this commitment through manufacturing advanced products. Thus, in corporate-wide training and education of engineers, a continual stimuli and integrated efforts are essential. The Institute of Technology has been established in 1990 in order to fulfil such needs.

Mitsubishi Electric's educational system has evolved over several decades and it includes practical and comprehensive in-depth Corporate Engineering Seminars. [1, 2] With the rapid increase in the number of young engineers at our facrories. Research laboratories and branches spread across the nation, the education system using satellite communications with minimum per-recipient cost was the center of its interest in the late 1980s. The distance learning is currently one of the most effective means to provide the engineering knowledge and information in time of needs. [3]

This report describes the overall system using satellite communications and its recent development. It briefly summarizes the results of comparative analysis of the questionnaires given to all the particpants over a period of each year, covering both the seminars using satellite communications, and those using the three education centers. [4] There is an emphasis on the importance of the practical in-depth education in computer-aided engineering (CAE) which is effectively linked by a computer network covering the Institute, research laboratories and the factories. [5] It also establishes a human network, which enables continued comunication between participants and helps mutual upgrading. This can be realized by the latest addition of various services, such as bulletin board and e-mail, through the intranet and mailing list services set up.

\section{Outline Of The Education System Using Satellite Communications ${ }^{3]}$}

\section{$2.1 \quad$ Overall Views and Equipment}

There are two satellite communications channels for education. They effectively support digital TV, or moving picture, specific to the aim and purpose of various courses. A still picture, i.e. snapshot from the moving picture, is also provided to help the student's comprehension. Corporate VAN is efficiently used for bidirectional communications between lecturer(s) and students. The students can ask questions by audio, and also answer quizes or questionnaires by selecting the right numbers on their desktop. Furthermore, selected pictures of a receiving room are sent to the studio by the continually upgraded corporate VAN (called MIND) to assist the lecturer. 
Since late 1994, the system started linking all the factories, research laboratories and branch offices, and now in 1997, there are 55 receiving sites. Lecturers can select the nearest studio either in the west or in the east of Japan. A typical lecturing scenes is shown in Figure 1.

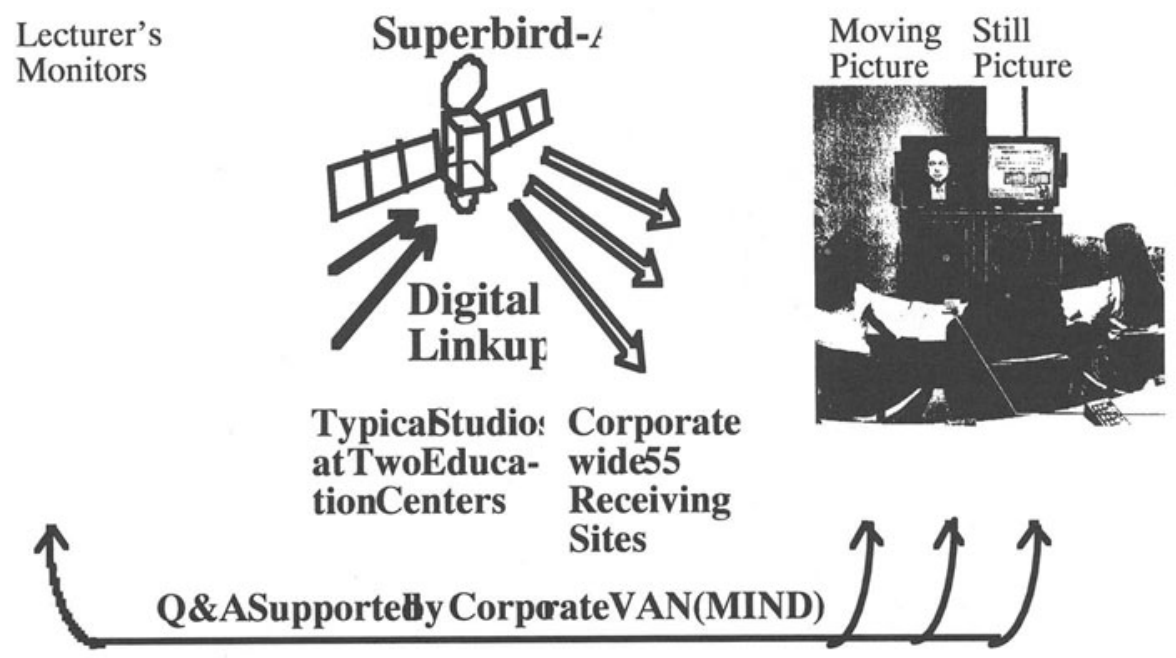

Figure 1. Utilization of satellite communications system with fiber-optic corporate 


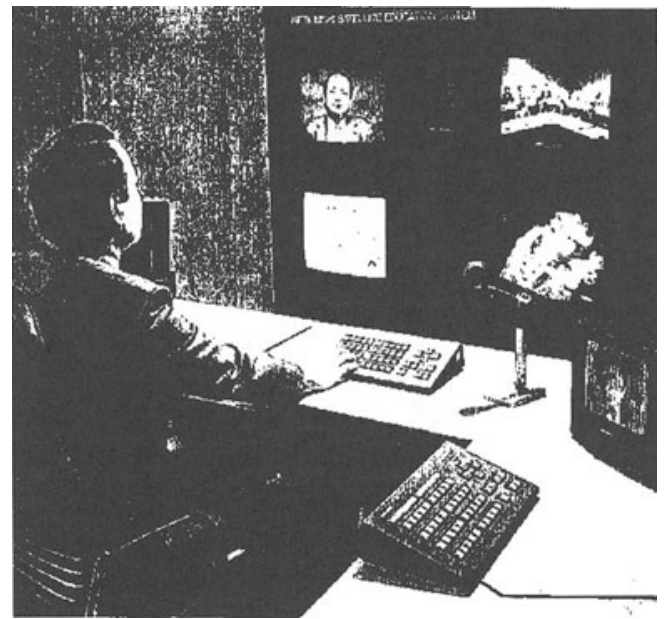

\subsection{Educational Programs Using Satellite Communications}

The following two educational programs, i.e. work-hours and after-hours program, fully occupied single-channel capacity since the fiscal year 1995 starting in April.

2.2.1 Work-hours Program There are three categories in the work-hours program (figures in 1997):

- 70 basic engineering courses with specialities such as in software engineering,

- 10 introductory engineering courses without specialities,

- 26 engineering-oriented business seminars called MBS'es, e.g. an accounting course, and a proprietary course. Each MBS usually covers a single topic.

The former two courses belong to the Corporate Engineering Seminars.

A basic engineering course consists of five topics, in contrast to an introductory one with two to three topics. According to the students' requirement, the student can attend course; by a unit of one topic, which increases the chance to study. Each topic takes three hours of the day. 
Table 1. Typical curriculums of the Seminars using satellite communications (e.g. four couses).

\begin{tabular}{|c|c|c|c|c|c|}
\hline & Mon & Tue & Wed & Thu & Fri \\
\hline $\begin{array}{l}\text { Morning } \\
\text { Session } \\
\left(\begin{array}{c}9: 15- \\
\text { 12:00 })\end{array}\right.\end{array}$ & Java1 & Java2 & $\begin{array}{c}\text { Inter- } \\
\text { net }\end{array}$ & $\begin{array}{c}\text { Inter- } \\
\text { neR }\end{array}$ & $\begin{array}{c}\text { Inter- } \\
\text { neB }\end{array}$ \\
\hline $\begin{array}{c}\text { Afternoon } \\
\text { Session } \\
(13: 15- \\
16: 15)\end{array}$ & $\begin{array}{c}\text { ISO } \\
14001 \\
1\end{array}$ & $\begin{array}{c}\text { ISO } \\
14001 \\
2\end{array}$ & $\begin{array}{c}\text { ISO } \\
14001 \\
\text { CALS }\end{array}$ & 1 & CALS \\
\hline
\end{tabular}

A typical course schedule is shown in Table 1. Lecturers give a short examination on each topic, and the results of those examinations are stored in a database to be used for later personnel development.

2.2.2 After-hours Program At present, twelve new or most popular topics are monthly selected to promote engineers' self-development. Lectures start at 5:30 p.m. on Tuesdays, Wednesdays and Thursdays. Some distinguished guest speakers are twice honored. New topics are constantly added to cover latest development, such as, in mobile communications, proprietary rights in multimedia era, and global warming.

\subsubsection{Typical Work-day Schedule and Overall Volume}

As stated before, a single-channel capacity is fully occupied. The time schedule and overall volume of engineer education for the fisical year'97 are summarized in Figure 2. 
(A good portion of

seminars are

specific to certain types

of com-

puters, thus held

separately for

system engineers and

customers.)

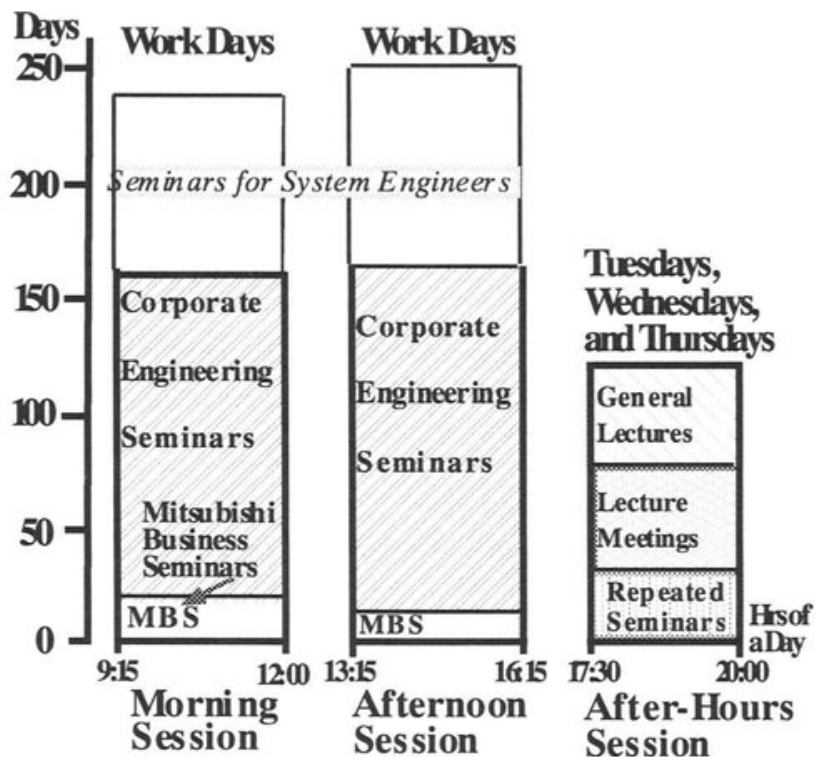

Figure 2. Time schedule and overall volume of the engineer education using satellite communications.

\subsection{Latest Development and Some Results Achieved}

Thus, by carefully selecting suitable topics and using the satellite communications for visual images, such as in-house videos, real models, photos and illustrations, the next two points have been found:

1. The number of attendees or person-courses to the Corporate Engineering Seminars has rapidly increased.

In the fiscal year 1996, the total number to the work-hours courses using the system has increased to about 5,800 person-courses, as this is shown in shadow in Figure 3. On the other hand, the after-hours program achieved 6,500 attendees (not shown in Figure 3). With reference to the number of engineers over some 20,000 , about $60 \%$ of the engineers receive the benefits of the education using satellite communications in each year. It can be also said that $25 \%$ to $35 \%$ of the Corporate Engineering Seminars are directly related to information and/or network technology, i.e. proportional to corporate's product share. 


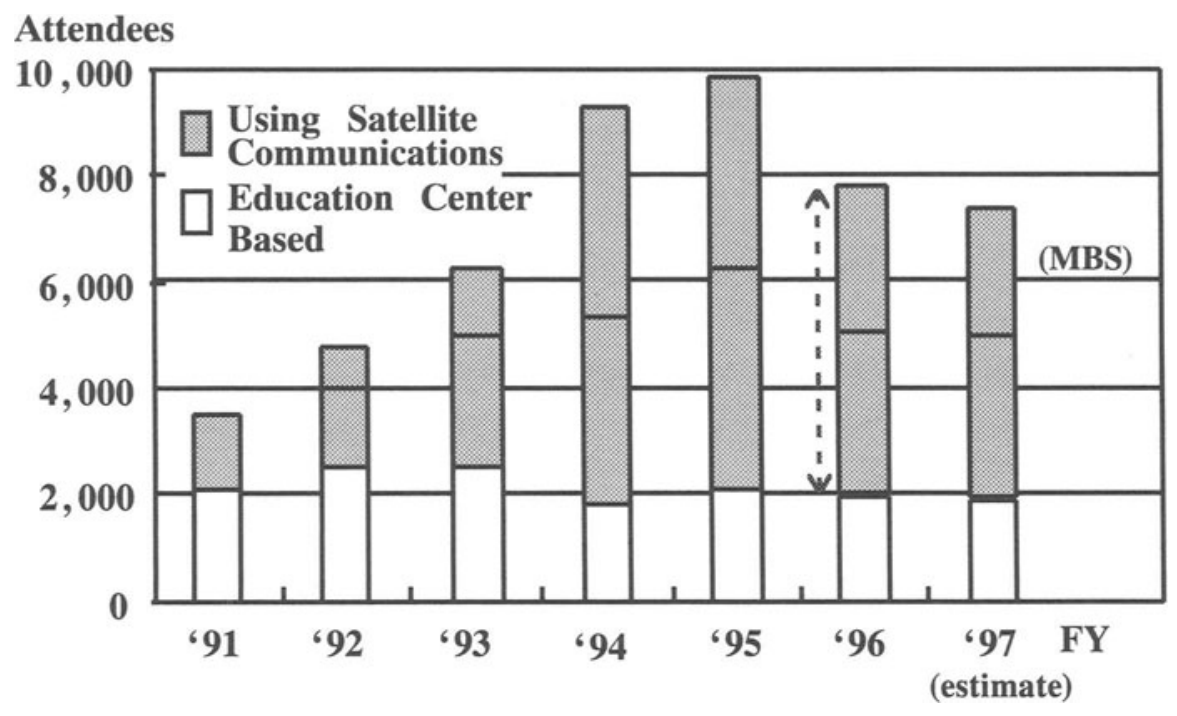

Figure 3. Number of participants of the corporate engineering seminars and engineering-oriented business seminars (MBS)

2. The cost and time spent on travelling to education centers have been reduced and minimized.

It should be noted that there are now participants having access to these education seminars while before they were physically unable to attend due to the distance to education centers.

\section{Analysis Of The Education System Using Satellite Communications ${ }^{[4]}$}

A series of questionnaires has been given to the participnants from the start of Corporate Engineering Seminars. A year of records have then been put into comparative analysis and it has revealed the effects of education through a satellite communication in comparison to a center based ones. The reasults are summarised below. 


\subsection{Standard Questionnaires Used and Analyzed}

In order to mainly evaluate a level of understanding, a sheet of short examination is given at the end of each topic lectured. The sheet also includes six standard questions in a scale of five, and they are as follows:

Q1: How useful in carrying out one's succeeding job

Q2: Well understood the contents of the topic

Q3: Level of difficulties regarding the topic's contents

Q4: Thorough cognition level of textbook

Q5: Cognition level of the flip chart used when lecturing

Q6: Topic suitable for using satellite communications
Useful 1 to Useless 5 , Understood 1 to Least 5 , Too High 1 to Too Low 5 ,

Easy 1 to Difficult 5 ,

Easy 1 to Difficult 5, and

Suitable 1 to Center-based 5.

Moreover, each sheet provides a good portion of space for freely writing questions and comments. All these questionnaires have well accumulated in fiscal year 1994, to 48 courses or 162 topics, to 12,780 person. In parallel to very similar questionnaires covering the education center-based 90 courses or 1,665 personcourses, a comparative study was carried out upon all the data obtained by above, according to a standard statistical procedure.

\subsection{Questionnaires Analysis and Some Distinctive Features Obtained}

In order to understand the result easier, the mean of the person-topics sum of each topic is normalized so that the maximum scale-point of each topic calculated becomes a degree of a hundred. Therefore, in case of $\mathbf{Q} 2$ on the degree of understanding, the histogram of the topic frequency is shown in Figure 4.

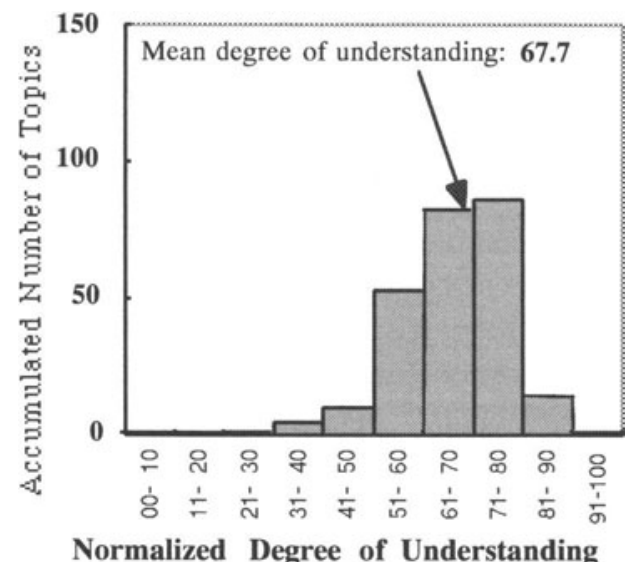

Figure 4. Histogram of 12,780 topics classified around normalized degree of understanding.

It is clear that the best understanding is less at the class of 91 to 100 degree. The mean degree of understanding appears around 67.7. A similar figure is found for the center-based education at around 68.6, which shows that by effectively using the satellite communications, the education is as effective as the center-based one. 
Apart from most of the similarities obtained under the comparative study throughout, some distinctive features are also found useful when all the correlation diagrams of which are compared among the six questions Q1 to Q6, two are shown in Figure 5. In case for the textbook evaluation in Figure 5a, relatively strong correlationship exists between the textbook and the degree of understanding (correlation coefficient 0.78 ). This is less in case of center-based seminars (correlation coefficient 0.24 , not shown), although specific textbooks are commonly prepared beforehand as a form of bound lecture notes in four weeks in advance of prior study and preparation for the short examinations given. Similarly, well prepared flip chart is effective on understanding, as this can be seen in Figure 5b. It
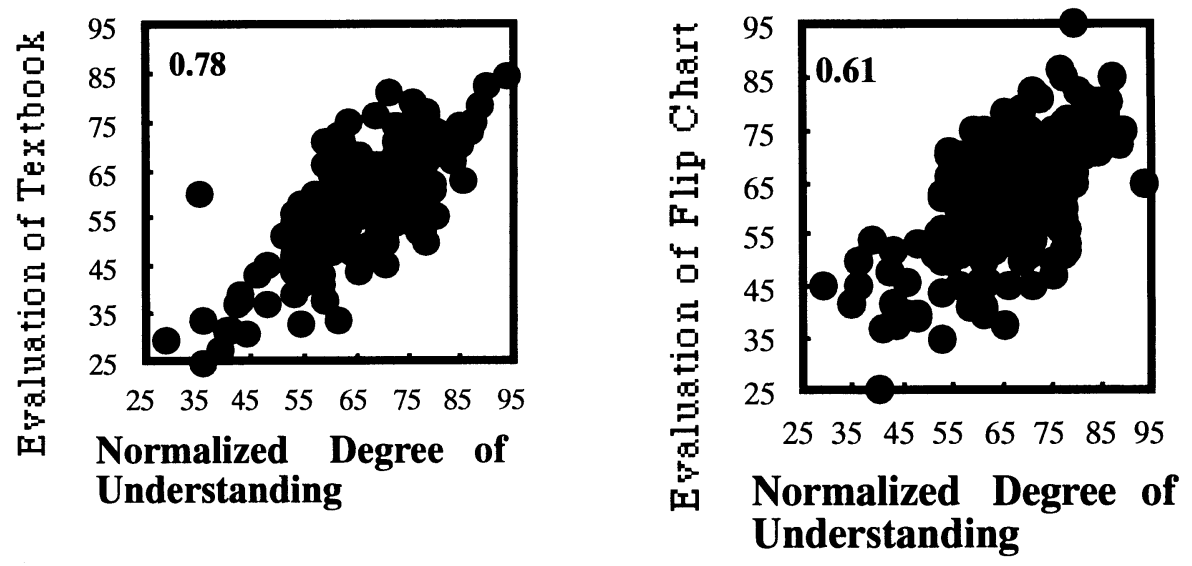

Figure 5. Correlation diagrams for the evaluation of textbook(a) and flip(b) chart with reference to the normalized degree of understanding covering 12,780 topics.

has by now revealed that, owing to the distinctive features of the distance education using satellite communications or alike, the lecturers are strongly advised to prepare well-organized and best-fit textbooks, and tailored lecturing materials provided by means of visual images such as in-house videos, real models, photos and illustrations. 


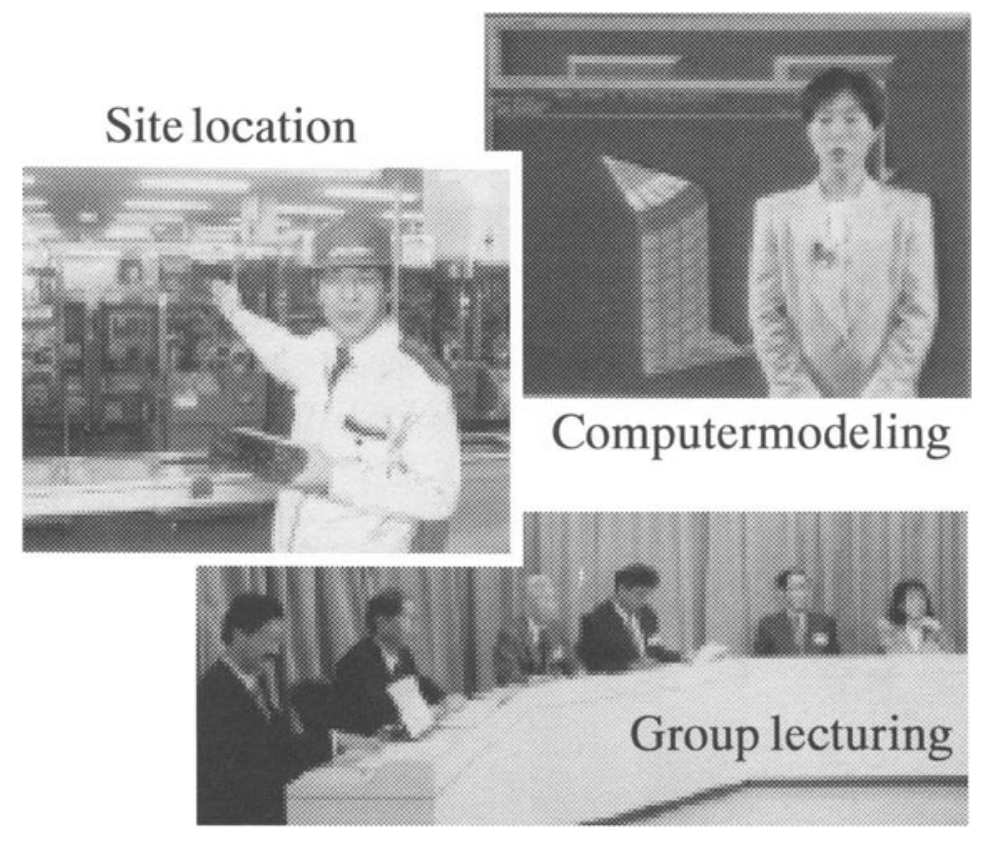

Figure 6. Lecturing scenes with visual images supported by a production team.

To assist lecturers coming to participate from elsewhere within the corporation, a production team is steadily reinforced to create lecturing materials required. Some lecturing scenes are depicted in Figure 6. For example, site location is relatively convenient and strongly effective by showing real things going. With the advent of powerful but low cost personal computers, direct presentation and analytical modeling are getting wide popularity these days. Group lecturing is useful to cover common topics with wider point of views.

Finally, questions and comments are also carefully classified with reference to most to least understood topics. The following features have been found effective by many attendees.

- Practical examples shown by way of videos, and directly from personal computers,

- Before going into the specific details, overall guidance of the relevant topic is given,

- Wordings are properly given before actually used for the profession,

- Story construction is straightforward, and interesting throughout the lecturing, and 
- Image information is well knitted and plentiful, but not excessive to follow after.

\section{Distance Learning Using Satellite Communications and Various Media Including The Intranet And Mailing List}

Since 1983, corporate-wide engineering seminars and workshops have been organized and continually upgraded to cover basic to advanced engineering fields. Satellite communications have been implemented since 1990, to cover nation-wide attendees with minimal per cost, and also to provide basic courses required common to those engineers new to or fresh in the technology. In-house videos and computer desktops are used to describe the basic concept and functions of various products, manufacturing process, evaluation strategy, regulations required, etc. Each of the two studios covers all the current 55 receiving sites including all the office branches.

More advanced and up-to-date courses are annually revised to fit in inter-works requirements, and to exchange the design experiences in the product fields mutually related. Intensive three to five day seminars and workshops are set up based on three education centers to accomplish problem solving tasks of individuals.

A human communications network also provides an important contribution to upgrade those course attendees by means of the e-mail and bulletin board which enable the required consultation on demand among all the participants. With the popularity of the Internet and sufficient proliferation of e-mail especially since 1995 , some additional services are rapidly provided to augment the bidirectional features especially found indispensable for distance learning. Staff members of the Institute and people in the network and information technology lead the following activities to service:

- Intranet server provides the schedule and brief contents of all the seminars.

- In addition to printed guidebook electronic forms are made available with ease.

- E-mail server accepts mailing list services based on the tasks and/or technical fields, thus most of pre-course information is given, and relevant questions followed after.

- Some network related courses provide corresponding home pages which enable the attendees ask questions by e-mail and obtain course materials used by the lecturers. 


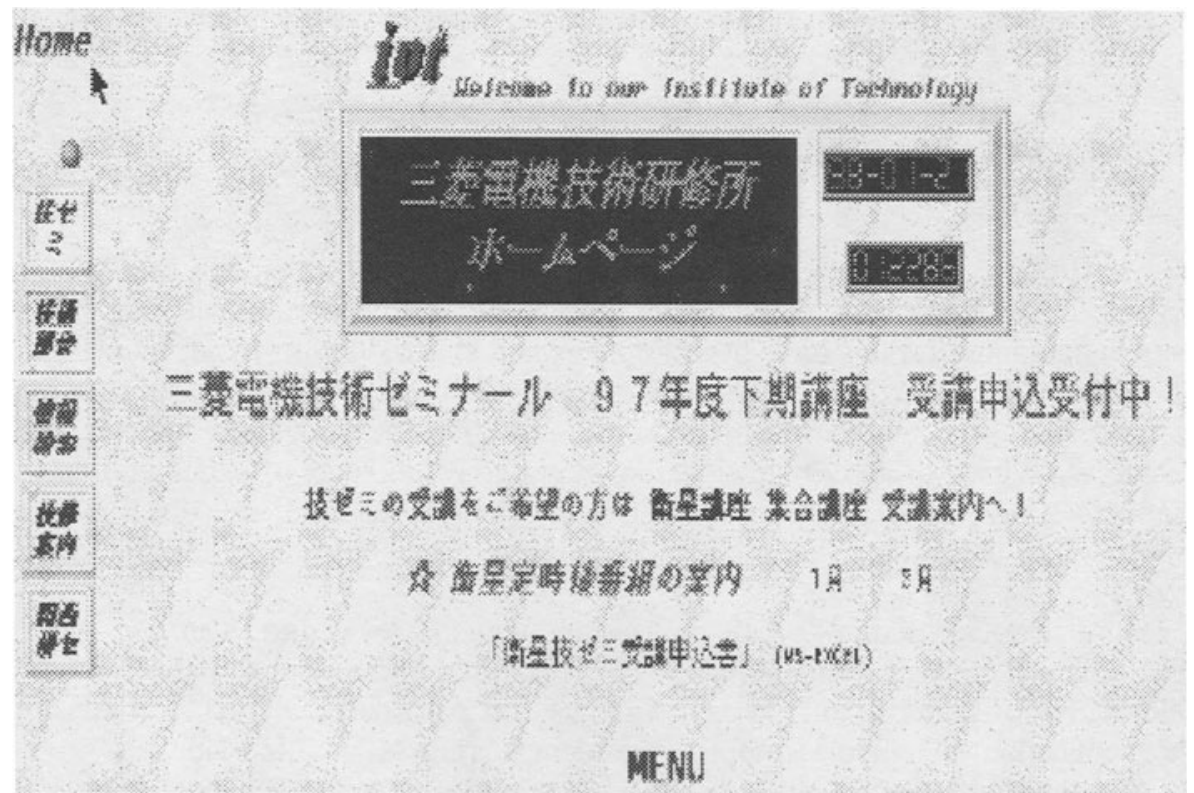

Figure 7. Part of the home page of the Institute of Technology 


\section{Conclusion}

Mitsubishi Electric Corporation, established in 1921 as an electrical machinery manufacturer, has grown to a general electric and electronics manufacturer, expanded a range of products toward systems, and considerably improved its efficiency of the production. Its unique engineer education system has been developed according to the corporate culture, an indispensable role company wide. It is considered that the advancement in the "knowledge creation" is a key factor to continue attaining the prosperity, and to realize a lively society toward the next century.

By using satellite as a main means to provide education to engineers over distance, it has made such education efficient and effective. It has achieved increase in the quantity of education provided at low cost. Additional efforts in the 'visual information' or 'bidirectional communications', provision of well-constructed and suitable textbooks can increase the quality of such educational efficiency.

Education using satellite communications enables simultaneous feeding of the knowledge and information required, but also enhancing the fundamental corporate culture for human resource development. Over seven years, our institute has been active to advance the practicality and effectiveness in engineer education. It stimulates the active learning environments among the engineers. In cooperation with the center-based courses and lately attempting the intranet, "spontaneous education provided upon demand" can be fulfilled by using satellite communications with comprehension.

\section{References}

1. Gamo, Y., Hisha, H., Yamada, I., and Ohara, Y., "Continuing Engineering Education System in Mitsubishi Electric Corporation." In Proceedings of 5th World Conference on Continuing Engineering Education (WCCEE), June 2-5 1992, Espoo, Finland. pp. 739-744.

2. Shimada, W., and Hisha, H.: "Continuing Engineer Education in Mitsubishi Electric Corporation Implementing the 'Active Learning' Strategy Best Fit for the Individuals." In Congress Proceedings of World Congress of Engineering Educators and Industry Leaders, UNESCO '96, July 2-5 1996, UNESCO, Paris, France. Volume II, pp. 35-40

3. Nishio, A., Sakai, K., Koga, K., Shimada, W., and Hisha, H., "Corporate-Wide Distance Education for Engineers Using Satellite Communications in Mitsubishi Electric Corporation.” In Proceedings of 2nd Mid-Term AEESEAP International Conference on Engineering Education, April 23-26, 1996, Makuhari, Chiba, Japan. Paper T6-5 (4p.)

4. Kasuga, M., Nishio, A., Tohda, H., and Odaka, T., "Analysis of Attendees' Evaluations on Each Type of Education: Education Using Satellite Communications and Center Based Education at Mitsubishi Electric Corporation." Journal of Japanese Society for Engineering Education (JSEE), Vol. 45, No. 3, May 1997. pp. 41-45 Japanese 
5. Yoshinaga, K., Hisha, H., and Sakabe, S.: "Power Engineering Education Utilizing Satellite Communications and Computer Networks." In Proceedings of International Conference on Energy Management and Power Delivery (EMPD) '95, November 21-23, 1995, Singapore. IEEE, 1995 pp. 485-491

\section{Biography}

Kouji Yoshida recieved the B.Sc.(1972) from Okayama Univ., Japan. He then went on to be a Computer Scientist in the Information Engineerig Works at Mitsubishi Electric Corp, Kamakura Japan. He took part in the development of CAD or CG on the large-sized computer. He is currently a Research and education Scientist in the Institute of Technology. His major research includes Internet/Intranet, distance learning and information gathering on the Internet. He is one of the members of IPSJ, IEICE Japan.

Asako Nishio received B.A.(1991) from Kyoto Univ., Japan, in psychology. since then, she has been engaged in the education of corporate engineers using satellite communications at Mitsubishi Electric's Institute of Technology.

Hiroshi Hisha received B.Sc. (1973) from Hiroshima Univ., Japan, M.Sc. (1975) from UMIST, England, and Ph.D. (1983) from Univ. of Canterbury, NZ, in power systems engineering. He then joined Mitsubishi Electric's Itami Works, to pursue diagnosis application of microelectronics to gas-insulated switchgears. His main interests include the career development of corporate engineers through the Institute of Technology. Members of IPSJ, IEICE Japan and IEEJ.

Harumasa TOHDA received B.Eng.(1974) from Univ. of Tokyo, Japan, inMechanical engineering. He then joined Mitsubishi Electric's Central R\&D Lab., to the pursue developpment of practical structural analysis methods to turbo-generators and large ntennas. His main interests include the education of corporate engineers through the Institute of Technology. A member of the Japan Society of Mechanical Engineers.

Tadashi ODAKA received B.Eng.(1966) from Osaka Univ., Japan, in electric engineering, and M.Sc.(1969) in physics from Kobe Univ., Japan, . In 1971, after two years research work in Kobe Univ., he joined Mitsubishi Electric's Central R\&D Lab., to pursue materials characterization using electron beams. His main interests include education of the corporate engineers through the Institute of Technology. A member of the Japan Society of Applied Physics.

Masahiro KASUGA received B.Sc.(1992) from Waseda Univ., Tokyo, Japan, in ergonomics. He then joined Mitsubishi Electric's Institute of Technology, to pursue multimedia-based practices in engineering education. His main interests include multimedia service systems and new business development currentl at the Kansai Branch Office. 